\title{
IMPRENTA Y GOBIERNO MUNICIPAL EN BARCELONA. SEBASTIÁN Y JAIME MATEVAT AL SERVICIO DEL CONSELL DE CENT (1631-1644)
}

por

\section{Carlos Pizarro Carrasco}

Universidad de Barcelona

RESUMEN: Desde que en 1631 le fue concedido a Sebastián Matevat el privilegio de imprimir para el Consell de Cent de Barcelona, tanto él como Jaime Matevat se encargaron de publicar las ordenaciones, edictos y cartas reales, así como las alegaciones y memoriales jurídicos que defendieron los intereses de la institución en las polémicas políticas contra la Corona. A partir de 1640, la Guerra de los Segadores amplió las necesidades editoriales del consistorio y permitió la participación, además de los impresores de la Ciudad antes mencionados, de otros talleres tipográficos barceloneses: Sebastián de Cormellas y Pere Lacavalleria; a este último se le encargó ese mismo año una de las ediciones de la "Proclamación Católica» de Gaspar Sala; fue entonces, también, cuando se multiplicaron los panfletos y los papeles menores destinados a la organización de la defensa militar del Principado: carteles, circulares y pasaportes. Entre las fuentes utilizadas en este artículo, destacamos la importancia de los libros de contabilidad del gobierno local o "Memorials de Comptes del Clavari», cuya consulta debe completarse con las deliberaciones municipales y la bibliografía impresa por Sebastián y Jaime Matevat para la ciudad.

Palabras Clave: Barcelona. Producción impresa. Edición institucional. Siglo XVII. Consejo de Ciento.

ABSTRACT: From the moment when, in 1631, the Consell de Cent of Barcelona granted Sebastian Matevat the right to print his works, be and Jaime Matevat undertook the publication of the ordinances, edicts, royal letters, juridical declarations and briefs defending the interests of the institution during the political polemics against the Crown prior to the Catalan Revolution. From 1640, the revolt extended the editorial needs of the town council and allowed other printing shops to take part in municipal production: Sebastian de Cormellas and Pere Lacavalleria; that year, the latter took charge of one of the editions of Gaspar Sala's Proclamación Católica. 
During the same period, a large number of pamphlets and papers printed to organise the militar defence of Catalonia, appeared the scene: placards, circulars, short letters and passports. Among the sources used in this article are the account books of the Consell de Cent or "Memorial de Comptes del Clavari», which need to be complemented with the records of municipal deliberations and the bibliography that Sebastian and Jaime Matevat printed for the city.

KEY WORDS: Barcelona. Printed production. Institutional publishing. XVIIth century. Consejo de Ciento.

En 1675 Melchor Cabrera Núñez de Guzmán, abogado de la Corte, publicó el Discurso legal, histórico y político en prueba del origen, progresos, utilidad, nobleza $y$ excelencias del arte de la imprenta. La obra, que reivindicaba para el oficio de impresor la condición de «arte liberal» - $y$, por tanto, la exención de impuestos para los libros- constituye, tal vez, el primer compendio español sobre la imprenta ${ }^{1}$.

Entre los temas tratados en esta obra estampada en Madrid por Lucas Antonio de Bedmar, el que más nos interesa aquí es la admiración que mostraba el autor por la actitud positiva de las instituciones castellanas hacia la actividad tipográfica:

"Y conociendo algunas ciudades y poblaciones del Reyno que con la Imprenta dan vezes a su autoridad, se abre puerta a que los naturales se alienten a la virtud y a las letras, y se conservan los medios a la buena política y govierno, la ban llevado, assegurando a los duenos, estipendios y ayudas de costa»

En su alegato, Melchor Cabrera Núñez de Guzmán concretaba las diferentes medidas que habían tomado en cada ciudad determinadas autoridades políticas, religiosas y educativas en apoyo de la imprenta: concesión de ayudas de costa y privilegios editoriales, creación de los impresores oficiales e incluso, en el caso de Granada, la exención del pago de tributos a todos los tipógrafos. Los gobiernos locales ocupaban un papel destacado en este impulso y algunos disponían de un impresor público con una remuneración periódica, como era el caso de Bilbao, León, Sevilla y Jaén².

\footnotetext{
1 A lo largo del siglo XVII existe en España una copiosa literatura reivindicativa, en forma de memoriales dirigidos al rey o de alegaciones jurídicas escritas por abogados próximos a los Consejos, en defensa de la imprenta y de los profesionales del libro; algunos ejemplos son Por la libertad de los libros (1636), de Blas Dorante, y el mencionado discurso de Cabrera Núñez de Guzmán. Está también la Institución y origen del Arte de la Imprenta y reglas generales para sus componedores (1680), esta vez a cargo de un tipógrafo, Víctor Alonso de Paredes, quien dedica una mayor atención a los aspectos técnicos del oficio.

2 CABRERA NÚNẼz DE GUZMÁN, Melchor: Discurso legal, bistórico y político en prueba del origen, utilidad y nobleza del arte de la imprenta, edición facsímil (estudio introductorio de Amalia Sarriá Rue-

Hispania, LXIII/1, núm. 213 (2003) 137-160
} 
El cargo de «impresor mayor» de la capital hispalense, hereditario, se inició en 1657 a partir de Juan Gómez de Blas; éste también llegó a encargarse oficialmente de las publicaciones de la Catedral, la Inquisición, la Universidad, y «todos los cabildos y tribunales». En Zaragoza tenemos el ejemplo de Diego Dormer (1632-1674), que fue también «impresor de la ciudad» y legó este privilegio a sus herederos. Sin embargo, parece ser que uno de los tipógrafos municipales pioneros en la Monarquía Hispánica ejerció sus funciones en Pamplona, Carlos Labayen, que era designado por sus regidores (1607) como «impresor de la ciudad y del Reino de Navarra» para imprimir «cédulas y otros despachos»3${ }^{3}$.

Los tipógrafos de las universidades ocuparon un papel mucho más destacado en la producción de libros, debido a la necesidad continuada de publicación de textos escolásticos y docentes. Podía darse el caso de pies de imprenta en los cuales aparecía solamente la referencia a la institución educativa, algo que sabemos que sucedía en la imprenta complutense. Precisamente, el primer «impresor de la Universidad» en Alcalá de Henares fue, a partir de la década de 1620, Juan de Orduña. Aunque hubo otras universidades como la de Huesca y Salamanca que contaron también con un tipógrafo oficial, destacamos aquí la actividad de la dinastía de los Lanaja (1607-1684), quienes permanecieron al frente de los impresos universitarios en Zaragoza - algo que reflejan los Estatutos de $1645{ }^{4}$.

Frente a la existencia de numerosas portadas en obras publicadas en Barcelona, durante el siglo XVII y hasta el Decreto de Nueva Planta, que hacen alusión a un «impresor de la ciudad» o «impresor de la ciudad y su universidad», nos interesa aquí centrarnos en la política editorial a nivel municipal y, muy especialmente, en la figura del tipógrafo del Consell de Cent. Además, teniendo en cuenta la invasión de folletos jurídicos y propagandísticos que tuvo lugar en las décadas anteriores y durante la revolución catalana de 1640-1652, resulta imprescindible analizar las repercusiones específicas del contexto político-militar en la producción impresa del gobierno local.

\section{LA POLÍtiCA EDITORIAL DEL CONSELL DE CENT EN EL SIGLO XVII: UNA APROXIMACIÓN}

Antes de pasar a profundizar en la figura del impresor municipal de Barcelona, conviene echar un vistazo al conjunto de situaciones en las que el consistorio desarrollaba o fomentaba la actividad editorial. No se trata de un estudio

da), Madrid 1993, ff. 21-22. Agradezco al Dr. Fernando Sánchez Marcos, Profesor Titular de la Universidad de Barcelona, que me haya facilitado el acceso a este libro.

3 VV.AA.: Historia ilustrada del libro español. De los incunables al siglo XVIII, Madrid 1994, págs. 165, 180-181. Delgado CASADO, Juan: Diccionario de impresores españoles (siglos XV-XVII), Madrid 1997, vol. 1, pág. 284.

4 VV.AA.: Historia ilustrada..., págs. 160, 172 y ss. 
sistemático de la documentación municipal existente, y sólo pretendo establecer algunos modelos provisionales basados en los ejemplos consultados 5 .

En primer lugar, encontramos obras de autor que recibían ayudas de costa. En los dos ejemplos analizados, los autores habían escrito de motu propio un manuscrito que dedicaban al municipio, y solicitaban ante la comisión de gobierno una subvención económica para sufragar los gastos de publicación; por ser un asunto de índole económico, la decisión de otorgarla en cada caso debía tomarla el pleno del Consell de Cent, lo cual retrasaba la tramitación. Como veremos a continuación, el hecho de que se tratara un tema de interés municipal o que el solicitante fuera un antiguo funcionario local podía influir poderosamente en la concesión del subsidio:

En agosto de 1609 el Consell de Cent de Barcelona proporcionaba a Jeroni Pujades, una ayuda de costa de 500 libras para gastos de impresión de la Crònica Universal del Principat de Catalunya, después de haber aprobado la estampación del texto, que el autor le dedicaba; habían transcurrido más de cinco años desde que, en febrero de 1604, el jurista barcelonés había presentado el original y solicitado financiación al Trentenari del gobierno local. A pesar de que el pie de imprenta de Jeroni Margarit está fechado en 1609, el libro no salió a la luz, según asegura Pujades en su Dietari, hasta mediados de $1610^{6}$.

En septiembre de 1613 el Consell de Cent otorgaba 400 libras a Joan Francesc Rossell, doctor en Medicina por la universidad de Barcelona, después de que hubiera suplicado ayuda para imprimir un «Commentari de Galeno de morbo et synthomatum»:

«(...) Y sobre aquella [suplicatiól, lo dit Consell delibera que per la impressió del sis llibres que segons ba dit y referit lo mateix doctor Rossell entén y vol imprimir, li sian donades 400 lliures, les quals se hagen ha convertir en ajuda de gasto de la impressió de dits llibres y no en altra effecte».

La ayuda de costa, que fue entregada en cuatro plazos de 100 libras cada uno, no acabó de ser pagada hasta julio de 1627. El primero y único volumen de Ad sex libros Galeni De differentis et causas morborum E symptomatum commentarii, fue impreso ese mismo año por Sebastián y Jaime Matevat ${ }^{7}$. La obra, de

\footnotetext{
5 Algunas de las referencias siguientes aparecen en FLORENSA SOLER, Núria: El Consell de Cent: Barcelona i la Guerra dels Segadors, Barcelona 1996, págs. 351-352.

6 Arxiu Històric de la Ciutat de Barcelona (AHCB), Consell de Cent, Deliberacions, II-113, 1604, f. 42. Dietari de Jeroni Pujades, edición a cargo de Josep Maria Casas Homs, vol. 1, Barcelona 1975-76, f. B. 233. Las diligencias pudieron demorarse debido a que el autor residía habitualmente en Castelló d'Empúries, donde era abogado fiscal del Duque de Cardona. Sobre el Trentenari, v. nota infra.

7 AHCB, Consell de Cent, Deliberacions, II-122, ff. 263-264 (26-9-1613); ibid., II-136, ff 35, 76,101 . En lo sucesivo, los Matevat seguirían trabajando para el autor, como demuestra la edición en 1628 del Curationum medicinalium centuriae septem de Amatus Lusitanus, y la impresión de El verdadero conocimiento de la peste (1632).
}

Hispania, LXIII/1, núm. 213 (2003) 137-160 
una extensión considerable (más de mil doscientas páginas), contiene en la portada el emblema calcográfico de Barcelona con la mención «fecit Ioannes de Courbes». La vinculación de Joan Francesc Rossell con la ciudad no acaba aquí, ya que fue conseller en cap en dos ocasiones (1623 y 1638), y, en 1632, dedicó al gobierno municipal uno de sus libros, El verdadero conocimiento de la peste.

En segundo lugar, hemos hallado alguna obra de autor - que tampoco parece haber sido encomendada por el consistorio- cuya publicación la financiaba íntegramente la hacienda local. En 1642 fue editado Breu.Tractat d'Artilleria, escrito por Francesc Barra, maestro de la Escuela de Artillería de Barcelona, y que, en plena Guerra de los Segadores, resultaba de gran interés para la administración barcelonesa; el libro sería estampado en el taller de Jaime Matevat. ${ }^{8}$

Asimismo, debió de ser muy habitual la financiación completa de obras de pequeña envergadura que habían sido previamente encargadas, tanto a funcionarios locales como a autores independientes. Numerosos memoriales jurídicos eran redactados por los abogados de la institución y estampados por los «impresores de la ciudad», gracias al papel suministrado por el librero oficial. ${ }^{9}$ Por otro lado, a principios de 1636 los consellers acordaban costear la publicación de un texto escrito por el fraile agustino Gaspar Sala a instancias del Hospital de la Misericòrdia de la ciudad y que estaba dedicado a la administración local, el Govern Politich de la Ciutat de Barcelona, pera sustentar los pobres y evitar los vagamundos (1636), el cual sería impreso por Sebastián y Jaime Matevat, «impressors de la ciutat y sa universitat»:

«que sien girades de compte ordinari als administradors de dit hospital 100 lliures, ab les quals ajen y degan fer stampar dit llibre y pagar tots los gastos que per occasió de exir aquell a llum se bauran de pagar (...)» ${ }^{10}$.

Finalmente, quiero incluir el caso de un proyecto editorial que partió de la súplica presentada por la Cofradía de Libreros de Barcelona ante el Consell de Cent. El 26 de agosto de 1624, ante la sucesión de ediciones gramaticales comentadas de Nebrija y Erasmo que eran utilizadas en la enseñanza universitaria de la ciudad, los comerciantes de libros reclamaron que las obras fueran refundidas en textos únicos para así evitar también el perjuicio económico que ocasionaba tener que renovar constantemente la oferta de tratados de Gramática en sus tiendas. Parece ser que el consistorio accedió a la petición, aunque

8 Véase ESPINO LóPEZ, Antonio: «La milicia de Barcelona en los siglos XVI y XVII», en Barcelona. Quaderns d'Història (Barcelona) 5 (2001), págs. 205-215.

9 v. infra.

10 AHCB, ibid., II-145, f. 42v (14-1-1636). Concretamente, la obra fue impulsada por la Comissió dels Trenta-dos perteneciente a la institución benéfica; véase FLORENSA SOLER, Núria: «L'assistència social i l'aportació econòmica del municipi barceloní al segle XVII a malalts, prostitutes, pobres, vagabunds, belitres i bargants», en Barcelona. Quaderns d'Història (Barcelona) 5 (2001), págs. 193-204. 
no hemos podido localizar la existencia de dichos textos refundidos durante los años siguientes a la misma ${ }^{11}$.

El llibreter de la Casa de la ciutat era un cargo que permitía a la corporación local garantizar el suministro de material de papelería para sus oficinas, oficiales e impresores, y conseguir, por tanto, una producción editorial propia. Desde su creación a finales del siglo XV, un reducido número de familias de libreros permaneció como proveedoras de las plumas, tinta, papel para la escritura y libros administrativos que debían utilizar los consellers y Consell de Cent, oficiales, Archivo, Lonja, Taula de Canvi y los porteros de la muralla; además, se convirtieron en intermediarios en la compra de papel destinado a los tipógrafos, y en encuadernadores de los impresos municipales ${ }^{12}$.

Al menos desde 1482 existía la figura institucional del librero municipal, entonces Antoni Ramon alias "Corró». A pesar de la oposición de gran parte de los vendedores de libros que trabajaban en Barcelona, asociados en cofradía desde 1553, el cargo siguió en manos de la dinastía de los Corró (Cortey). Como mínimo a partir de que Rafael Nogués fue nombrado librero de la ciudad, en 1586, se empieza a cobrar un salario ${ }^{13}$. En 1613 el oficio pasó a una tercera familia, los Vives (originarios de Cervera), que conservaron las mismas atribuciones casi ininterrumpidamente hasta 1661: Rafael Vives (padre), y desde 1619 en colaboración con su hijo Rafael Vives i Femades; Joan Sapera (16381639); interinidad del escrivà racional Jeroni Sabata (1639-1640); y vuelta de Rafael Vives i Femades, quien permaneció hasta 1661. Posteriormente, lo ejercieron Rafaela Castelló (1661-1688), Ramon Sapera (1688-1706) y Francisco

11 Véase AHCB, Deliberacions del Consell de Cent, 1624, f. 145; citado por GonZÁlez SUGRAN̄ES, Miguel: Contribució a la bistòria dels antics gremis, dels Arts y oficis de la Ciutat de Barcelona. II: Llibreters. Estampers, Barcelona 1918, págs. 23-24. Por su parte, el artículo de GuilleuMAS, Rosa, «Sobre les edicions gramaticals erasmianes impreses a barcelona als segles XVI i XVII», en VV.AA.: Homenaje a Jaime Vicens Vives, Barcelona 1967, vol. II, págs. 213-230, nota 1, hace referencia a unas Institutiones Latinae de 1625 impresas por Esteve Liberós a instancias del Consell de Cent y a expensas de la cofradía que, al parecer, recogían diversas obras de Antonio Nebrija y de Erasmo. Por el momento, no he podido confirmar la existencia de esta edición.

12 Una fuente documental de extraordinaria utilidad para el estudio de esta figura institucional son los Memorials de Comptes del Clavari. El máximo responsable de las finanzas municipales, o clava$r i$, apuntaba en este libro los gastos que se iban realizando a cuenta de la ciudad por la prestación de servicios y la compra de material. Afortunadamente, en muchos de los volúmenes (que abarcan cada uno un período de dos años) existe un índice con las fechas de cada cuenta, persona acreedora y su oficio, y concepto de la deuda. Respecto a los libreros de la ciudad, podemos obtener datos sobre el suministro de artículos de papelería (cronología, clases, precios y destino del papel entregado), la encuadernación y el reparto de ejemplares de libros entre los oficiales del municipio.

13 GonZÁlez SugraÑES, Miguel: Contribució a la bistòria..., vol. II, págs. 34, 40-41. 
Sapera (1706-1714), hasta que el Decreto de Nueva Planta eliminó definitivamente el Consell de Cent de Barcelona ${ }^{14}$.

Tal vez el pilar fundamental de la participación de la institución local en la actividad editorial era el impresor de la ciudad. Durante el siglo XVII y la Guerra de Sucesión podemos confirmar que trabajaron como tales las siguientes impresores: Sebastián y Jaime Matevat, Viuda Matevat, Josep Forcada, Caterina Matevat, Teresa Cormellas y Joan Pau Martí15.

Para conocer la clase de impresos municipales que eran encargados por el Consell de Cent al tipógrafo oficial, nos será de gran utilidad tener en 1624 , siete años antes de que se produjera el primer nombramiento, hallamos a un supuesto impresor barcelonés llamado «Matheu Matavat» que presentaba una petición ante el consistorio para que fuera nombrado:

«impressor de la present Ciutat y de la universitat del Studi General de dita Ciutat de tots los memorials, conclusions y altres coses que (...) se hauran d'estampar» 16 .

Efectivamente, la consulta de los libros de cuentas del clavari demuestra que la mayor parte de la producción tipográfíca municipal a partir de 1631 está formada por impresos menores de utilidad jurídica y política, tales como ordenaciones, edictos, memoriales y alegaciones jurídicas, pleitos, cartas reales, y relaciones de sucesos.

14 ibid., pág. 41-43. El autor cita algunos documentos: AHCB, Consell de Cent, Deliberacions, 1619, f. 140; ibid., 1638, ff. 232v-233. Por otra parte, hallamos suministros de material de papelería llevados a cabo por libreros no oficiales: Francesc Gombau, vendedor de telas (AHCB, ibid., f. 630, 812-1640) y Sebastián de Cormellas, mercader, librero e impresor (AHCB, ibid., f. 514, 17-10-1640).

15 Sobre la dinastía Matevat, v. infra. Tras la muerte de Paula, viuda de Sebastián Matevat, Josep Forcada fue nombrado impresor de la Ciudad, véase AHCB, Consell de Cent, Deliberacions, II160, f. 465 (4-11-1651), antes de ser restituido el cargo a la familia anterior en febrero de 1652 en la persona de Caterina Matevat, hija de Sebastián y Paula, véase AHCB, ibid., II-163, f. 123 (29-21652). El próximo nombramiento lo hallamos en 1675, cuando Teresa Cormellas y Ginebreda, viuda de Sebastián Cormellas hijo, accede al oficio tras haber quedado vacante desde la muerte de Caterina, véase AHCB, ibid., II-149, f. 86-86v, 11-3-1675. El Doctor José Cormellas, su hijo, podría ser el siguiente en la lista, justo antes de Joan Pau Martí, véase MARTí, Joan Pau: Excel.lentíssim Senyor. Per la renúncia que feu lo Doctor Joseph Cormellas..., Barcelona [1684 o post.], f. II, aunque faltaría contrastar esta información con los archivos municipales; el documento es una alegación jurídica en defensa de este propietario de imprenta que se halla catalogada en la Biblioteca de Catalunya con el número de registro 10283. En cuanto a Joan Pau Martí, tenemos constancia que fue también «estamper del General i de la casa de la Diputació», véase BURGos Rincón, Francisco Javier: Imprenta y cultura del libro en la Barcelona del setecientos: 1680-1808, tesis doctoral dirigida por Ricardo García Cárcel, Universitat Autònoma de Barcelona 1993, vol. 1, pág. 499.

16 AHCB, Consell de Cent, Deliberacions, II-133, f. 118 (5-7-1624). No me consta que existiera un Mateu impresor en la familia, por lo que es muy posible que se trate, en realidad, de Sebastián Matevat, que era el único representante de la familia que en 1624 podía demostrar una experiencia tipográfica suficiente para aspirar a semejante cargo. 
El primer nombramiento hallado pertenece a Sebastián Matevat, que era designado en 1631 "estamper de la Ciutat y de sa Universitat del Studi General», un cargo no asalariado que otorgaba el monopolio en la impresión de los papeles municipales, cobrando únicamente por trabajo acabado ${ }^{17}$. Desde este momento y hasta 1644, numerosos pies de imprenta confirman esta condición de impresor de la Ciudad, si bien observamos algunas irregularidades: a menudo aparece el nombre de Sebastián junto al de su hijo Jaime - que no se menciona en el nombramiento-; además, no siempre encontramos la referencia a la universidad y, lo que es más importante, con demasiada frecuencia hallamos la alusión a dicha condición de tipógrafo municipal en obras que fueron estampadas para libreroseditores particulares que nada tienen que ver con el gobierno local.

Los libros de contabilidad del clavari son la fuente que nos proporciona una información más completa sobre las impresiones realizadas a instancias de la institución, si bien en las deliberaciones del Consell de Cent podemos hallar algunas referencias aisladas, tales como el mandato de impresión o la orden de pago por la misma. Por un lado, las cuentas a nombre de los libreros especifican la clase, la cantidad y el precio del papel que era entregado (normalmente por orden del escrivà racional o de un oficial notario) a la imprenta; la imprecisión de los términos con que se refiere a las obras nos impide realizar un seguimiento cronológico exhaustivo de la producción a partir de estos datos ${ }^{18}$. En cambio, los asientos en concepto de las impresiones concluidas, que estaban encabezados por la referencia al tipógrafo, facilitan la identificación de los títulos, el número de ejemplares y el precio que debe pagar la ciudad por el servicio; además, al final de cada registro hallamos la fecha de la deliberación consistorial que le corresponde. También nos es posible detectar la presencia del grabado calcográfico en las obras, debido a que éste no podía estamparse, por razones técnicas, junto a los caracteres tipográficos; así, en más de una ocasión hallamos un apartado donde se consigna la impresión de una plancha fina con las armas de la ciudad que va destinada a la portada. ${ }^{19}$

No quería concluir este repaso a la política editorial barcelonesa de la época sin hacer referencia a Joan de Courbes y a su escudo de Barcelona. El grabador francés se destacó por sus servicios en la Corte española durante la década de los veinte y los treinta del siglo XVII (si bien estuvo en su país natal en 162326), y trabajó para Lope de Vega, el padre Rojas y José Pellicer, entre otros; se especializó en retratos y portadas, aunque también realizó frontispicios e inte-

17 AHCB, Consell de Cent, Deliberacions, f. 142, 30-7-1631.

18 El mejor estudio sobre los molinos papeleros del Principado, las clases de papel y su comercialización, MADURELL, Josep Maria: El paper a les terres catalanes, Barcelona 1972, contiene múltiples referencias a la distribución destinada a los impresores barceloneses -los Matevat, entre ellos-

19 Sobre los memoriales de cuentas, $v$. nota supra. La plancha mencionada es el escudo calcográfico de Barcelona firmado por Joannes de Courbes, $v$. infra.

Hispania, LXIII/1, núm. 213 (2003) 137-160 
riores de páginas ${ }^{20}$. En 1627 localizamos la primera portada con el escudo de plancha fina de Barcelona en Ad sex libros Galeni De differentis et causas morborum..., el tratado médico de Joan Francesc Rossell. Desde entonces, comprobaremos que esta lámina aparece únicamente en obras municipales importantes en tamaño folio estampadas por Sebastián y/o Jaime Matevat como impresores de la ciudad, lo que nos hace suponer que la matriz original fue diseñada exclusivamente para el consistorio y adquirida por estos tipógrafos ${ }^{21}$; sin embargo, el grabado en cobre más reconocido por su calidad artística y riqueza iconográfica es la estructura arquitectónica que acapara el frontis de la Vida $i$ echos maravillos... de doña María de Cervellón... con algunas antigüedades de Cataluña (1629), escrita por Esteve de Corbera e impresa por Pere Lacavalleria, uno de los profesionales más destacados de la imprenta barcelonesa del momento.

\section{SEBASTIÁN Y JAIME MATEVAT:' IMPRESORES DE LA CIUDAD Y DE LA UNIVER- $\operatorname{SIDAD}(1631-1644)$}

Considerada la segunda imprenta más importante de Barcelona en el siglo XVII después de la casa Cormellas, la dinastía Matevat —o Matevad, Mathevat, Mathevad e incluso Matavat - se dedicó, fundamentalmente, a la publicación de relaciones de sucesos, copias de cartas, pliegos poéticos, sermones y textos legales. A partir de los pies de imprenta, podemos establecer una cronología de su actividad tipográfica: Sebastián Matevat (1605-1641), Jaime Matevat (1620-1644), Viuda Matevat (1644-1650), Catalina Matevat (16531657), Sucesores Matevat (1659-1687)22.

Sebastián Matevat empezó a trabajar en Barcelona en 1605 asociado con Onofre Anglada, y después, en 1608 y 1609, con Llorenç Déu; al año siguiente

20 Sobre Joannes de Courbes, véase MATiLla, José Manuel: La estampa en el libro barroco. Juan de Courbes, Vitoria 1991; véase también GAllego y GAllego, Antonio: Historia del Grabado Español, Madrid 1979, págs. 156 y ss.

21 J.M. Matilla afirma que las láminas de Courbes que se incluyen en libros editados en otras localidades (Valladolid, Salamanca, Alcalá, Sevilla, Granada o Barcelona) debieron ser grabadas desde su estancia en Madrid y remitidas posteriormente a provincias, véase op. cit., pág. 3.

22 Delgado Casado, Juan: Diccionario de impresores españoles..., vol. 1, págs. 442-446. La viuda Matevat es Paula Umbert, véase AHCB, Notarial, III-21 (9-III-1664?), que acostumbra a aparecer en la documentación con el apellido de casada de su marido Sebastián Matevat; agradezco al Consejo de Redacción de Hispania que me haya facilitado esta referencia de archivo. Después de la muerte de Sebastián y de Jaime, Paula adquirió el taller y, como nueva propietaria del mismo, heredó el cargo que estaba en propiedad de su difunto esposo -y que también había disfrutado su hijo Jaime- (1645-1651), hasta que falleció a causa de la epidemia de peste que asoló Barcelona en 1651, véase AHCB, Consell de Cent, Deliberacions, II-154, ff. 69v-70 (4-2-1645); AHCB, ibid, II-163, f. 123 (29-2-1652). Respecto a Catalina Matevat, fue tipógrafa oficial del Consell de Cent a partir de $1652 \mathrm{y}$, muy probablemente, se trata del último representante de la familia de impresores, ya que hizo testamento hacia 1664 en favor de «la noble Sra. doña Maria Sans», viuda de don Lluís Sans, véase AHCB, Notarial, ibid. 
inició su andadura en solitario y a partir de 1620, hasta el final de su trayectoria profesional, lo hizo la mayor parte de las veces junto a Jaime Matevat. Ubicado, al menos desde 1615, delante de la Rectoría de Nuestra Señora del Pino, entre sus obras barcelonesas destaca la Historia de San Oleguer (1617) de Antoni Joan García de Caralps y la primera edición conjunta de las dos partes del Quijote, impresa el mismo año en colaboración con el también barcelonés Bautista Sorita. Se supone también una estancia efímera en Barbastro (1621-1622), donde estampó los tres tomos de las Homilías sobre los Evangelios de Jerónimo Bautista de Lanuza. En 1631 fue nombrado «estamper de la Ciutat y Universitat», lo que le permitió centrarse más en el suministro de los impresos municipales de Barcelona hasta 1641, fecha de su muerte ${ }^{23}$. La consulta de los pies de imprenta refleja que a lo largo de su trayectoria imprimió también para numerosos libreros-editores particulares, tales como Miquel Manescal, Joan Simon y Sebastián Cormellas.

Jaime Matevat inició su actividad tipográfica en 1620 junto a su padre ${ }^{24}$. Desde que Sebastián fue nombrado «impresor de la ciudad», hallamos también a Jaime estampando impresos menores para el municipio. Uno de sus trabajos más destacados son las Faules (1642) de Esopo, donde podemos constatar la utilización de una marca de impresor propia, la cual ya había sido empleada en el siglo XVI por los talleres barceloneses de Claudi Bornat y Jaime Cendrat ${ }^{25}$. Sin embargo, no se ha detectado entre la producción municipal de los Matevat el uso de ninguna imagen gráfica que los identifique, excepto, quizás, la frecuencia con que aparecen determinadas combinaciones de caracteres tipográficos en algunas cabeceras. Jaime Matevat murió en 1644 y fue relevado al frente del taller por su madre Paula ${ }^{26}$.

23 Delgado CaSado, Juan: Diccionario de impresores españoles..., ibid. La muerte de Sebastián Matevat está registrada en Arxiu Històric Parroquial de Santa María del Pi (APSMP,) Llibre d’òbits, armario Y, estant. V, vol. 143, fol. 112v (13-3-1641).

24 Pese a que murieron en fechas muy próximas, Sebastián y Jaime Matevat no eran hermanos como aseguran DeLGADo CASADO: Diccionario de impresores..., vol. 1, op. cit., pág. 443, y ETTINGHAUSEN, Henry: La Guerra dels Segadors a través de la premsa de lèpoca, Barcelona 1993, vol. 1, págs. 28-29. La documentación hallada no suele especificar la relación familiar entre ambos, pero hay algunas excepciones que confirman la opinión de RÀFOLS, J.F. (dir.): Diccionario biográfico de artistas de Cataluña., Barcelona 1951, vol. 2, pág. 150, que los considera padre e hijo. Véase AHCB, Consell de Cent, Memorial de Comptes, XII-10, 1632-1633, f. 787v; Arxiu de la Catedral de Barcelona (ACB), Esposalles, vol 79, 1637-39, f. 23v., documento que corresponde al matrimonio de Jaime con Eulàlia, hija de un campesino de Caldes de Montbui.

25 VINDEL, Francisco: Escudos y marcas de impresores y libreros de España, Barcelona 1942, pág. 347. La imagen es la ${ }^{\circ} 45$. Se trata de la marca alegórica que aparece en la portada de las Faules de Isopo y que podría hacer alusión a la virtud (las hojas de olivo) y el poder (el águila), como cualidades de la imprenta al servicio del orbe cristiano (el globo culminado con la cruz). Algunas de las marcas de impresor atribuidas en la obra de Vindel a Sebastián y a Jaime no son sino emblemas que ilustran sobre el contenido de los textos, véanse las págs. $344\left(\mathrm{n}^{\circ} 442\right), 345\left(\mathrm{n}^{\circ} 443\right)$.

26 Sobre Jaime Matevat, Delgado CASAdo, Juan: Diccionario de impresores..., vol. 1, op. cit., pág. 444, añade que tuvo librería; lo cierto es que su nombre no figura en la nómina de la Cofradía

Hispania, LXIII/1, núm. 213 (2003) 137-160 
1631-1637: Una etapa marcada por el conflicto jurídico-político con la Corona

La actividad oficial de Sebastián y Jaime Matevat al servicio del consistorio tiene su punto de partida en la deliberación de 30-7-1631 del Consell Ordinari dels Trentasís ${ }^{27}$, en la cual se admitió a Sebastián Matevat, tras haber estudiado su petición, como «estamper de la dita Ciutat y de la Universitat del Studi General»; esta decisión, que se decía fundamentarse en los muchos años que llevaba trabajando para la institución educativa, le permitía ponerse al frente de las impresiones municipales y universitarias, «sens salari algú y sols pagant-li lo que estampera» para dichas instituciones ${ }^{28}$.

Durante este período anterior a la Guerra de los Segadores, Sebastián y Jaime Matevat ejercieron un monopolio casi absoluto sobre las publicaciones del Consell de $\mathrm{Cent}^{29}$. Las dificultades en la consulta de la documentación de 1638 y 1639 me impiden aventurar ninguna conclusión sobre este bienio, aunque sí daré algunas referencias aisladas sobre las publicaciones que salieron a la luz. Debido a la variedad e interés de las materias que van apareciendo durante la etapa analizada, he optado por clasificar la producción por temáticas y géneros:

Un primer bloque de asuntos impresos está formado por la legislación y la acción del gobierno de Barcelona. El funcionamiento administrativo del Consell de Cent exigía que para la primera convocatoria anual del consejo se hubiera repartido a cada uno de los asistentes un ejemplar de las ordenaciones de la institución; así, en 1633 y 1637 tenemos registradas dos impresiones (la segunda de ellas de doscientos cincuenta ejemplares) de las denominadas «Ordinacions del nou redres del Consell de Cent de 1632», un folleto que se decía tener una extensión de dos pliegos de impresión. ${ }^{30}$

de Libreros de Barcelona que se haya transcrita en GONZÁLEz SUGRAÑES, Miguel: Contribució a la bistòria..., vol. 2, op. cit., pág. 76.

27 El Trentenari o Consell Ordinari era una comisión integrada por 36 individuos que representaban a todos los estamentos y se renovaban cada trimestre; examinaba semanalmente las cuestiones que se habían presentado y decidía sobre ellas — con algunas limitaciones-, lo que permitía agilizar la adopción de acuerdos municipales. Véase PALOS, Joan Lluís: Catalunya a limperi dels Austria, Lleida 1994, pág. 394.

28 AHCB, Consell de Cent, Deliberacions, f. 142, 30-7-1631. La única referencia que hemos hallado sobre la experiencia anterior al servicio del Estudio General es el pie de imprenta de la Història de Sant Oleguer (1617) de García de Caralps, con la mención: «Sebastián Mathevat, impressor de la Universitat». Sobre una posible solicitud de monopolio anterior a 1631, v.supra.

29 Los memoriales de cuentas de esta etapa reflejan un monopolio sin fisuras en manos de los Matevat, si bien en los catálogos bibliográficos podemos dar con un «Redreç i ordinacions» del Consell de Cent sobre la recaudación en los portales de la ciudad que fue impreso por Sebastián de Cormellas en 1637.

30 AHCB, Consell de Cent, Memorials de Comptes, XII-10, 1632-33, f. 796 (23-10-1633); ibid, XII-12, 1636-37, f. 676 (5-9-1637). Probablemente se hacían tiradas largas para ahorrarse el tener que imprimirlo cada año. En 1706 Joan Pau Martí reimprimía un «Redreç i ordinacions» del Con-

Hispania, LXIII/1, núm. 213 (2003) 137-160 
La política municipal relativa a la pobreza se mostró favorable, desde finales del siglo XVI, a la reclusión de los pobres y vagabundos en el Hospital de la Misericòrdia. Al igual que la Corona y la Diputació del General, la ciudad de Barcelona también se preocupó por emitir y publicar numerosos edictos contra los vagabundos para evitar altercados urbanos. Las Crides fetes y estatubides per los Molt Illustres senyors concellers ... a fi y efecte de recullir tots los pobres de dita ciudad en lo Hospital de Nostra Senyora de la Misericòrdia (1633) están reunidas en un folleto de dos pliegos firmado, precisamente, por dos autoridades encargadas de mantener el orden público, el batlle de Barcelona y el veguer ${ }^{31}$.

El marco legislativo local sobre el abastecimiento de trigo en Barcelona también queda recogido en la producción tipográfica de los Matevat. La documentación municipal habla de la existencia de dos "Ordinacions dels forments", un folleto de 1626 y otro, cuya extensión alcanzaba los cuatro pliegos (uno más que el anterior), que era publicado en 1635 por orden del Consell de Cent. Según parece, el mismo año y en 1637 se imprimieron un total de setecientas copias y algunos carteles relacionados con el tema ${ }^{32}$.

En segundo lugar, tenemos que hablar de las repercusiones editoriales de la Guerra de los Treinta Años, y muy especialmente, del enfrentamiento contra Francia iniciado en mayo de 1635. A partir del mes de septiembre los libros de cuentas del municipio incluyen la entrega de papel para la impresión de «negocis secrets» o de "negoci de la guerra», y es más que probable que los Matevat hubieran acabado varios de estos trabajos en los meses posteriores, aunque no queden registrados en dicha documentación. De hecho, Sebastián y Jaime están considerados los pioneros, desde 1637, en la publicación de hojas de noticias en castellano, con el nombre de «Cartas», «Nuevas» o «Relaciones»; la mayor parte de estos folletos relataban episodios del conflicto militar europeo ${ }^{33}$.

sell de Cent de 25 de octubre de 1632 sobre la regulación de los gastos de los consellers, véase catálogo Biblioteca de la Universitat Pompeu Fabra (BUPF); aunque la obra original ha desaparecido, la coincidencia en la extensión del folleto entre la reimpresión de 1706 (ocho páginas en tamaño folio) y los datos de los dos memoriales de cuentas de 1632 (dos pliegos, que doblados por la mitad e impresos por las dos caras hacen las ocho páginas), ayuda a pensar que se trate de las mismas «Ordenacions del nou redreç del Consell de Cent de 1632» que menciona la documentación.

31 AHCB, Consell de Cent, Memorials de Comptes, 1632-33, f. 796 (23-10-1633). La factura, a nombre de Jaime Matevat, no especifica el número de ejemplares estampados. No he hallado el ejemplar impreso.

32 AHCB, Consell de Cent, Memorials de Comptes, XII-11, 1634-35, f. 394 (5-9-1635); AHCB, ibid., XII-12, 1636-37, f. 676 (5-9-1637). La documentación no deja claro cuántos ejemplares se imprimen de cada obra. Si recurrimos, una vez más, a reediciones posteriores de estos dos folletos, hallamos dos trabajos de 1678 a cargo de la imprenta Cormellas -entonces administrada por Vicens Surià- que nos completan la información sobre las obras originales: el primer texto tenía su origen en la reunión del Consell de Cent de 5-7-1626, mientras que la elaboración de la segunda obra era encomendada durante el consejo de 9-8-1635.

33 TORRENT, Jaime; TASís, Rafael: Història de la premsa catalana, Barcelona 1966, págs. 22-23. Añade también que la primera hoja de noticias en catalán fue impresa por Francesc Martorell en 1639 , en Tortosa.

Hispania, LXIII/1, núm. 213 (2003) 137-160 
Finalmente, destacamos el grupo de impresos municipales más significativo de este período: los memoriales jurídicos y los discursos políticos. A partir de las Cortes inacabadas de 1626 y del rechazo al proyecto militar y fiscal de Olivares conocido como Unión de Armas, se abrió una crisis política entre la Corona y el Principado que se tradujo en una eclosión excepcional de escritos e impresos de naturaleza jurídica e ideológica en Cataluña. Aunque no fueron pocos los sermones, panfletos y opúsculos anónimos, la literatura institucional aprovechó más la amplia experiencia de una serie de reconocidos juristas, letrados y doctores en leyes, en materia de pleitos o enfrentamientos entre entidades públicas, e incluso entre particulares ${ }^{34}$ :

Así, durante el transcurso de las Cortes de 1632 se encendió la polémica por la petición que hicieron los consellers de la ciudad de permanecer con la cabeza cubierta ante el monarca, privilegio reservado a los Grandes de España. Numerosos impresos fueron publicados en Barcelona, y a los Matevat les fue encargada la tirada de mil quinientos ejemplares de un «memorial de la cobertura», que no es otro que el opúsculo escrito por varios letrados encabezados por Pere Joan Rossell, titulado Por la ciudad de Barcelona, en justificación de la prerrogativa que tiene de cubrirse y sentarse sus conselleres (1632); en la portada se halla el escudo calcográfico de Barcelona de Joannes de Courbes ${ }^{35}$.

Otro debate político importante estuvo motivado por las exigencias tributarias de la Corona sobre la ciudad. Entre las obras de contenido jurídico que fueron publicadas sobre el pago del quinto real, el Consell de Cent mandó a Jaime Matevat mil doscientos cincuenta ejemplares del Discurso a favor de la muy insigne ciudad de Barcelona en orden a su essención y franquesa de quinto, libro que había sido encomendado a Pere Antoni Joffreu, doctor en Derecho y, por aquel entonces, «abogado subrogado» de la capital catalana; el texto fue impreso en 1634 y, una vez más, se utilizó una plancha de cobre para grabar las armas de la ciudad en la primera página de cada copia ${ }^{36}$. Otra obra sobre este asunto cuya impresión no se recoge en los memoriales de cuentas, pero que también corrió a cargo de la ciudad, es Iuris allegatio in qua docetur civitatem Barcinonae non teneri ad solutionem quinti.. (1634); el grabado de la portada vuel-

34 SIMON TARRÉs, Antoni: Els origens ideologics de la revolució catalana de 1640, Barcelona 1999, pág. 209. Otra aportación destacada en el estudio de esta literatura jurídico-política es la de PALOS, Joan Lluís: Els juristes i la defensa de les constitucions. Joan Pere Fontanella (1575-1649), Vic 1997.

35 Sobre el escudo de Courbes, $v$. supra. Más adelante haré un seguimiento exhaustivo del proceso de publicación de este memorial, $v$. infra. Otras obras sobre la cobertura fueron dos discursos que imprimió Pere Lacavalleria en 1632, uno de ellos de Pere Antoni Joffreu, y que fueron costeados por el librero Andreu Roure. Véase el catálogo de la Biblioteca Universitaria de Barcelona (BUB).

36 AHCB, Consell de Cent, Memorials de Comptes, XII-11, 1634-35 (11 de noviembre de1634), f. 461. Concretamente, se habla de "un memorial de micer Antoni Joffreu a favor de la ciutat a cerca dels quints». Véase el catálogo de la BUB.

Hispania, LXIII/1, núm. 213 (2003) 137-160 
ve a ser el mismo, pero el pie de imprenta está a nombre de los dos tipógrafos municipales y el texto, firmado por varios letrados ${ }^{37}$.

Los escritos de los juristas y de los abogados de la ciudad también abordaron otras causas judiciales entre instituciones. La censura eclesiástica de 1634 contra Pere Sossies, Maestro de las Fuentes de Barcelona, por haber dejado sin agua durante unas horas los claustros de la catedral, recibió una respuesta editorial implacable por parte de la ciudad. Ese mismo año se imprimieron dos alegaciones jurídicas escritas por un grupo de letrados - entre los que figuran los abogados municipales Pere Joan Rossell y Joan Pere Fontanella-, la resolución favorable de una junta de teólogos locales, así como diferentes carteles para ser colgados en las calles ${ }^{38}$.

Fuera del período analizado, tenemos algunas referencias sueltas correspondientes a 1638, que abordan conflictos jurídicos contra otras instituciones y particulares. A mediados de año, una cuenta a nombre de Jaime y Sebastián Matevat refleja la impresión realizada de cuatro memoriales de la ciudad: uno contra el mercader Miquel Garcia, otro en la causa judicial que enfrentó a Barcelona contra la localidad de Caldes de Montbui, y udos memorials en fet y en dret» relativos a un litigio, que también se había iniciado ante la Real Audiencia, esta vez contra Esteve Gilabert de Bruniquer, antiguo síndico y notario público de Barcelona. ${ }^{39}$ A través de la consulta de los catálogos bibliográficos hallamos de nuevo una referencia sobre un pleito entre la administración local y un particular, el Memorial en fet per la ciutat de Barcelona contra Jeroni Pintor...(1638), obra presidida por un escudo de la ciudad en la portada ${ }^{40}$.

El impacto de la Guerra de los Segadores en los impresos municipales $(1640-1643)$

El inicio de la Guerra de Separación en la primavera de 1640 constituye un verdadero punto de inflexión en la producción tipográfica de la ciudad, al menos respecto al período 1631-1637.41 Ante las nuevas circunstancias, se ordenó

\footnotetext{
37 Véase el catálogo de la BUB.

38 Una de las alegaciones, Por la ciudad de Barcelona y Francisco Sossies...con el cabildo de la Iglesia Maior acerca de las censuras declaradas contra el dicho Sossies, contiene en su primera página el grabado de Joannes de Courbes. La única referencia a estos impresos que aparece en la documentación es la cuenta correspondiente a la entrega de papel, por parte del librero de la ciudad (entonces era Rafael Vives), de papel para hacer los carteles, véase AHCB, Consell de Cent, Memorials de Comptes, 1634-35, f. 302 (147-1634): «(...) a Mathevat, 17 mans de paper major per posar los cartells per los cantons per negoci de les fonts».

39 AHCB, Consell de Cent, Memorials de Comptes, XII-13, 1638-1639, f. 588.

40 Véase el catálogo de la BUB. La obra tiene 30 folios y está encuadernada en folio, algo habitual en los memoriales jurídicos.

41 Sería muy interesante conocer, por ejemplo, las repercusiones editoriales en Barcelona de la campaña de Salses en 1639. Desafortunadamente, resulta penosa la consulta de las cuentas de 1638

Hispania, LXIII/1, núm. 213 (2003) 137-160
} 
a los impresores la publicación de un abundante material logístico, ideológico y propagandístico que seguía las directrices de los intereses político-militares del Consell de Cent y de uno de sus organismos ejecutivos, la Junta de la Vint-iQuatrena de Guerra ${ }^{42}$.

Asimismo, 1640-1643 supuso también un cierto deterioro de la posición privilegiada de la casa Matevat en la prestación de dichos servicios, ya que Pere Lacavalleria y, sobre todo, Sebastián de Cormellas, participaron en esta literatura institucional y lo hicieron incluso con trabajos de mayor envergadura; además, escasean las referencias a Sebastián Matevat, que morirá en 1641, y rara vez hallamos pies de imprenta con la mención «impresor de la ciudad» junto al nombre de alguno de los miembros de la familia. Finalmente, en 1644 desaparecen las publicaciones de Jaime de la contabilidad municipal, aunque al menos hasta noviembre no perdemos el rastro de la recepción de papel destinado a su taller ${ }^{43}$.

Quisiera reiterar la importancia de los Matevat en los albores de la prensa catalana y en la difusión de una literatura combativa al servicio de la revuelta de 1640-1652. Precisamente, los historiadores Francesc Xavier Burgos Rincón y Manuel Peña se han referido a la existencia de una «imprenta militante» que apoyó a la revolución desde el terreno de la polémica y la propaganda; al frente de esta batalla mediático-ideológica estuvieron Sebastián y Jaime Matevat, Gabriel Nogués, Jaime Romeu y, en menor proporción, Pere y Antoni Lacavalleria y Pere Joan Dexen. ${ }^{44}$

Las hojas de noticias, en su mayoría, tenían un único pliego que aparecía ante el público en formato pequeño y doblado en 4 ó 8 páginas; ${ }^{45}$ una extensión breve y la ausencia sistemática del grabado calcográfico permitían que los trabajos de impresión de este tipo de obras resultaran asequibles para instituciones y particulares. En algunos casos, los impresores barceloneses recogían las

y 1639, ya que el volumen correspondiente (XII-13) no está indizado como el resto de los memoriales de cuentas.

42 Esta comisión temporal, que en principio estaba formada por veinticuatro jurats del consejo municipal, se encargaba de acordar medidas sobre los asuntos militares (fortificaciones, municiones y armas, pasaportes de salida de la ciudad, orden público, etc.), véase SERRA I SERRA, Griselda: «La Vint-i-Quatrena de Guerra. Mesures del Consell de Cent en començar la Guerra dels Segadors», en Barcelona. Quaderns d'Història (Barcelona) 5 (2001), págs. 217-223.

43 La última noticia sobre Jaime Matevat es una entrega de papel llevada a cabo por el librero municipal Joan Sapera: «Item, a primer de novembre, ab lo orde del senyor Soldevila, be donat a Jaume Matevat cinch raymas de paper per estampar les ordinacions", véase AHCB, Consell de Cent, Memorials de Comptes, XII-16, 1644-45, f. 708v.

44 Burgos Rincón, Francisco Javier; PeÑA, Manuel: «Aportaciones sobre el enfrentamiento ideológico entre Castilla y Cataluña en el XVII», en Actes del I Congrés d" Història Moderna de Catalunya. Universitat de Barcelona, Barcelona 1984, vol 2, pág. 561. SIMON TARRÉs, Antoni: «Els orígens ideològics...», op. cit., pág. 209. Más de un centenar de estos escritos se hallan en la Colección Bonsoms de la $\mathrm{BC}$.

45 EtTinghausen, Henry: La Guerra dels Segadors.., vol. 1, op. cit., págs. 14-15. 
noticias del extranjero a partir de la Gazette de Renaudot - plataforma propagandística de la política de Richelieu y de las victorias militares de Luis XIII-, las mandaban traducir al castellano o al catalán - a veces, podían encargarse personalmente - y las iban sacando a la luz con una cierta periodicidad; se da la circunstancia que la versión catalana de uno de los primeros resúmenes de noticias bélicas de Europa publicados durante la revolución catalana fue impresa por Jaime Matevat en $1640^{46}$. Por otro lado, y a diferencia de los impresos tipo gaceta, una parte importante de las relaciones de sucesos informaba sobre hechos militares puntales que habían acaecido en el Principado y Condados; así, por ejemplo, los Matevat estamparon un texto firmado por Joan de la Torra - probablemente un seudónimo- sobre las victorias de las tropas francocatalanas a principios de 1641, Breve y verdadera relación de la entrada del marqués de los Vélez en Cataluña y retirado de su exército de Barcelona..., publicado el mismo año ${ }^{47}$.

Sin embargo, a falta de datos precisos sobre quién encargaba y financiaba estos folletos informativos, sólo podemos considerar como producción municipal los que están registrados en los libros de contabilidad del clavari o en las Deliberaciones, tanto del Consell de Cent como de la Junta de la $24^{\mathrm{a}}$ de Guerra. Sabemos que esta comisión ordenaba imprimir y distribuía por toda Cataluña multitud de cartillas de noticias, o avisos, ocurridas en Barcelona o procedentes de otros lugares del Principado ${ }^{48}$. El 9 de julio de 1640 tenemos fechada una cuenta municipal sobre la publicación de tres manos - unas setenta hojas - de papel «per avisos als llochs de la costa (...) per la notícia d'alguns vaixells $d^{\prime}$ enemichs, perquè dessen avisos ab fochs i fums de fortalesa en fortalesa» ${ }^{49}$.

Aunque la mayor parte de los trabajos editadas por el gobierno local durante este período reviste un carácter marcadamente bélico, algunos de los impresos menores forman parte de las necesidades organizativas de la institución, como sucede con la nueva tirada (1640) de las ordenaciones de 1632, sin cuyos ejemplares no podía efectuarse la apertura del año político en el consejo de los 144 jurats. ${ }^{50} \mathrm{La}$ peste es otro de los motivos permanentes de preocupación en el gobierno municipal, de modo que en agosto se facturaba la impresión de doscientos carteles que debían viajar a la costa para que sus habitantes se previnieran contra la epidemia ${ }^{51}$.

No obstante, la mayor parte de producción tipográfica del Consell de Cent a partir de 1640 - carteles, cartas, circulares y salvoconductos- está clara-

46 Ibid., págs. 24-25, 28-29; un opúsculo supuestamente traducido por Jaime Matevat está reproducido por Ettinghausen con la ref. $\mathrm{n}^{0} 322$, véase op. cit.

47 Véase también TORRENT, Jaime; TASIS, Rafael: Història de la premsa catalana..., op. cit., págs. 22-23.

48 Véase Serra i Serra, Griselda: «La Vint-i-Quatrena de Guerra...», op. cit., págs. 217-223.

49 AHCB, Consell de Cent, Memorials de Comptes, XII-14, 1640-41, f. 46.

so Sobre la mencionada reimpresión, véase AHCB, Consell de Cent, Memorials de Comptes, XII14, 1640-41, f. 849. Son 400 ejemplares.

51 Ibid. Véase también AHCB, Consell de Cent, Deliberacions de Guerra..., f. 196v. 
mente determinada por la nueva situación de guerra. El reclutamiento de los somatenes, el aprovisionamiento de víveres y medios de transporte, así como la movilidad de las personas en tiempos de guerra son algunos de los asuntos más destacados:

En un primer episodio destacable, los abusos que cometieron en mayo los tercios instalados en Perpinyà provocaron una reacción en cadena en varios municipios catalanes, de manera que el 21 de junio de 1640 los consellers de Barcelona mandaron publicar las cartas enviadas desde los consistorios de Girona, Figueras, Peralada y Ceret, y decidieron reclutar quinientos hombres con destino a la capital del Rosselló; esta leva fue posible gracias a las cartillas que se imprimieron "sobre los sometents, per a cridar a la gent a Perpinyà»52. En agosto del mismo año destacamos la emisión de cientos de billetes que instaban a los propietarios barceloneses de carrozas a que las vendieran a la ciudad, otros para recordar a los juristas que debían hacer guardia en las portales de la muralla, la impresión de circulares (bolletas) para mandar a gente en somatén a uno de los cuerpos de guardia de los consellers, y de trescientos carteles para alzar a diversas poblaciones en armas; en enero de 1641 se estamparon otros trescientos que tenían que repartirse por la Cataluña rural («als llochs de la recollita»), para que se enviaran alimentos y hombres al campo de batalla ${ }^{53}$. También fueron emitidas algunas cédulas de desplazamiento, o pasaportes, destinados, probablemente, a los miembros de la institución municipal ${ }^{54}$.

Las «cartas reales» constituyen otra muestra inequívoca de la producción de impresos breves al servicio de la guerra. En una cuenta del clavari de octubre de 1640 tenemos registrada la impresión de seis resmas en cartas que se tenían que mandar «a la Magestad del Rey Nostre Senyor». En noviembre se contabiliza la publicación de nada menos que dieciocho resmas de «las lletres del Rey Nostre Senyor», probablemente enviadas por Felipe IV. A principios de enero de 1641, son ciento cincuenta hojas las epístolas «de su Magestad»ss.

Por último, además de los papeles menores, las imprentas que sirvieron al municipio durante los primeros años del conflicto también contribuyeron a la difusión de libros y memoriales con un fuerte contenido ideológico y propagandístico. Entre septiembre y noviembre de 1640 fueron publicadas nada

52 AHCB, Consell de Cent, Memorials de Comptes, XII-14, 1640-41, f. 46 (9-7-1640). Las cartas que fueron publicadas están reproducidas en ETTINGHAUSEN, H.: La Guerra dels Segadors.., I, ref. 3, bajo el título "Ab esta van còpies de dos cartas escrites la una per los jurats...».

s3 AHCB, Consell de Cent, ibid., ff. 19, 46, 849. Véase también AHCB, Consell de Cent, Deliberacions de Guerra, 1B-III, vol. II, 1640-41, ff. 49v, 196v.

s4 AHCB, Consell de Cent, Memorials de Comptes, XII-14, 1640-41, f. 849. Véase también AHCB, Consell de Cent, Deliberacions de Guerra...., f. 196v.

ss AHCB, Consell de Cent, Memorials de Comptes, XII-14, 1640-41, f.46, 347 y 849. Véase también AHCB, Consell de Cent, Deliberacions de Guerra, ff. 49v, 196v. Si insisto tanto en citar textualmente las referencias al monarca es por la proximidad de la ruptura con la Monarquía Hispánica y del acercamiento de Cataluña al rey francés Luis XIII, entre diciembre y enero de 1641.

Hispania, LXIII/1, núm. 213 (2003) 137-160 
menos que tres ediciones de la Proclamación Católica de Gaspar Sala: dos en el taller de los Matevat y una a cargo de Pere Lacavalleria; asimismo, tenemos registrada una cuenta de 200 libras por el papel y la impresión que había hecho Sebastián de Cormellas de mil quinientos ejemplares de un «memorial» ${ }^{56}$. En febrero de 1641, ya durante el período de tutela francesa sobre el Principado, la contabilidad del clavari vuelve a dejar constancia de un trabajo del tipógrafo anterior, esta vez valorado en más de 300 libras y en concepto de la impresión y la encuadernación de dos tiradas de mil quinientos ejemplares cada una, de una obra titulada "Varias noticias universales». ${ }^{57}$ Finalmente, en agosto 1643, con motivo de la muerte de Luis XIII, Jaime Matevat se hizo cargo de las mil copias de un sermón funerario que le dedicaba la ciudad y que también contenía en la portada el escudo calcográfico de Joannes de Courbes. ${ }^{58}$

\section{ANÁLISIS DEL PROCESO DE PUBLICACIÓN DE DOS IMPRESÓS MUNICIPALES: EL MEMORIAL DE LA COBERTURA (1632) Y LA PROCLAMACIÓN CATÓLICA (1640).}

El acceso a las propias obras y la abundante documentación del gobierno local relativa a prácticamente todo el proceso de edición de estos dos títulos (encargo, redacción, impresión y financiación, y en algún caso incluso encuadernación y distribución), nos permite dedicarles el presente apartado monográfico. Asimismo, se trata de dos memoriales jurídico-politicos que pertenecen a cada una de las etapas de la producción de los Matevat al servicio del Consell de Cent.

En 1632 varios abogados, al frente de los cuales estaba Pere Joan Rossell, escribieron un alegato en defensa del privilegio que tenían los consellers de permanecer cubiertos en presencia del Rey. La primera de las referencias documentales halladas menciona la reunión del Consell de Cent del 25 de septiembre, en la cual se emplazaba para cuatro días después la lectura pública del manuscrito ante el pleno del consejo. Durante dicha convocatoria se deliberó que fuera impreso con la mayor diligencia posible, para que se le enviara un ejemplar al virrey y otro a Olivares en respuesta a una carta suya; en caso de

\footnotetext{
56 La obra de Gaspar Sala será analizada con detalle, $v$. infra.. Sobre el segundo de los memoriales, cuyo titulo desconozco; véase AHCB, Consell de Cent, Memorials de Comptes, XII-14, 17-101640, f. 514; AHCB, Consell de Cent, Deliberacions de Guerra, II, 1640-41, f. 156v.

57 AHCB, Consell de Cent, Memorials de Comptes, ibid., f. 731. Podría tratarse de una reimpresión o una edición refundida de la Noticia Universal de Cataluña de Martí Viladamor, obra que también fue apadrinada por la ciudad y, según parece, había salido a la luz el 21 de diciembre de 1640, véase RUBÍ, Basili de: Les Corts Catalanes de Pau Clarís, Barcelona 1976, pág. 272.

58 Ibid., XII-15, 1642-43, 7-8-1643, f. 179. Seguramente se trata del discurso pronunciado por el Padre Jaime Roig el 20 de junio de 1643, véase Catálogo de la BUB.
} 
que no se hubiera podido acabar el trabajo la semana siguiente, se contemplaba remitir al valido la copia manuscrita ${ }^{59}$.

El trabajo no se terminó a tiempo, porque Sebastián Matevat no recibió la primera entrega de papel, según refleja la contabilidad de la ciudad, hasta siete días más tarde; el librero municipal Rafael Vives le suministró veintiocho resmas y, para la impresión de una plancha fina, tres resmas y media de papel genovés $^{60}$. El encargo tipográfico debió acabarse antes del día 16 de octubre, fecha de una cuenta a favor de los Matevat valorada en 55 libras, la cual registra la impresión de mil quinientos ejemplares del memorial (de diez pliegos de extensión) y de la hoja correspondiente al grabado calcográfico que iría en la portada; a estas 55 libras había que restar tres que correspondían a Esteve Liberós, también estampador, quien había tasado los impresos ${ }^{61}$.

La documentación hallada va más allá y confirma la participación de otros artesanos en la publicación del memorial de la cobertura. A finales de octubre de 1632 tenemos constancia de la encuadernación efectuada por el librero de trece de los ejemplares en tela de tafetán, doce de los cuales iban destinados a los diputats, los consellers y el clavari ${ }^{62}$. En las órdenes de pago emitidas entonces por el Consell de Cent se benefician otros personajes además de los Matevat y Rafael Vives: los abogados autores, que deben recibir 500 libras, el escribano que hizo la copia manuscrita para Olivares por no haberse acabado la impresión a tiempo (40 libras) y Joan Carmini, naipero, que cobraría 10 libras por haber pintado de rojo en cada portada el escudo de la ciudad que grababa Courbes ${ }^{63}$.

Por otra parte, en cuanto a la Proclamación Católica (1640) de Gaspar Sala, el hecho de que salieran tres ediciones entre septiembre y noviembre da una idea de la importancia política que tuvo para la institución municipal. La primera noticia que tenemos de la obra es la existencia de dos o más sesiones plenarias del Consell de Cent anteriores al día 4 de septiembre, en las cuales se encargaba la redacción de un «memorial, o manifest y proclamació al Rey nuestro señor (...)»y, posteriormente, se autorizaba su impresión tras la lectura pública del manuscrito ${ }^{64}$.

Al día siguiente, Pere Lacavalleria completaba el primero de los trabajos tipográficos, gracias a las 139 resmas y 8 manos de papel genovés de la mejor calidad que le había suministrado en su momento el librero municipal; de los más de treinta pliegos de impresión, que no incluían ninguna plancha fina, hizo dos mil copias valoradas en 272 libras. Tenemos conocimiento, también, de la participación de diez o doce artesanos (fadrins) tipógrafos en este encar-

\footnotetext{
59 AHCB, Consell de Cent, Deliberacions, II-141, f. 417v, 29-9-1632.

60 Idem, Memorials de Comptes, 1632-33, f. 667.

61 Idem, Memorials de Comptes, 1632-33, f. 787-787v.

62 Idem, Memorials de Comptes, 1632-33, f. 667.

63 Idem, Deliberacions, II-141, f. 436, 26-10-1632; idem, Memorials de Comptes, 1632-33, f. 796.

64 AHCB, Consell de Cent, Deliberacions, II-149, 1640-41, f. 338 (4-9-1640).
} 
go $^{65}$. El 6 de octubre se creaba en la Junta de la $24^{\mathrm{a}}$ de Guerra una comisión de cuatro jurats para distribuir un número indeterminado de copias impresas del memorial entre la nobleza y las autoridades de todo el mundo, a través de la red de comerciantes internacionales, «a effecte que lo contingut en dit memorial sie a tot lo món notori»; de hecho nos consta que la obra fue traducida en Holanda, y luego al francés. El mismo mes zarpaba un barco cargado de impresos de la ciudad - entre los cuales podría estar la Proclamación - y de la Generalitat con destino a Mallorca y Menorca ${ }^{66}$. Además, en recompensa a todos los servicios prestados, la ciudad otorgaba a Gaspar Sala la cátedra de Teología de la universidad barcelonesa, a propuesta de la Junta ${ }^{67}$.

La edición de Jaime y Sebastián Matevat de 1640 apareció también en octubre, de modo que una cuenta del clavari establecía a finales de mes que las autoridades locales debían pagar 246 libras y 15 sueldos en concepto de los mil quinientos ejemplares de la Proclamación Católica que habían impreso - como en el caso anterior- en papel genovés y por orden del Consell de Cent y la $24^{\mathrm{a}}$ de Guerra, así como por la estampa de una plancha «que se tira diferentment» en cada uno de ellos; la consulta de la obra, en tamaño folio, confirma la presencia en la portada del escudo calcográfico de Barcelona que diseñara Joannes de Courbes ${ }^{68}$.

La tercera edición de la Proclamación Católica corrió a cargo de Jaime Matevat y el resultado es un trabajo en formato cuarto y mucho más tosco que el anterior, presidido también por la plancha fina de Courbes y con una extensión similar en número de páginas; a estos rasgos generales hay que sumar la escasez de adornos tipográficos, la baja calidad de la impresión, letras más reducidas y una cantidad mayor de líneas por hoja (cuarenta, muy por encima de las veinticinco que encontramos en la tirada que había realizado Lacavalleria en 1640). Los mil quinientos ejemplares fueron estampados, probablemente, antes del 21 de noviembre, aunque el pie de imprenta señala el año siguiente, 1641, como fecha de publicación ${ }^{69}$.

65 AHCB, idem, ff. 240, 243-244, 347. Ninguna de las ediciones de Proclamación Católica había sido atribuida hasta ahora a Pere Lacavalleria; sin embargo, la coincidencia de los repertorios y catálogos bibliográficos con los datos de la documentación municipal (el año de impresión, la extensión y la ausencia de grabados calcográficos) y el hecho de que aparezca una marca o distintivo habitual en muchos de los trabajos de este impresor, la maceta con flores, no me dejan la menor duda respecto a su responsabilidad en la edición «en cuarto» de 1640 sin pie de imprenta que se conserva en BUB, Fons Antic, C-239/4/11-1. Véase también PALAU DOLCET, Manuel: Manual del Librero Hispanoamericano, vol. 14, Barcelona 1962, pág. 186, ref. 23824-nota.

66 AHCB, Consell de Cent, Deliberacions de Guerra, II (1640-41), ff. 118-205v, y f. 135v, respectivamente. Citado por SERRA I SERRA, Griselda: «La Vint-i-Quatrena de Guerra...», op. cit., pág. 221. La referencia a las traducciones de la Proclamación se halla en PALAU DOLCET, Manuel: Manual del Librero Hispanoamericano..., pág. 186.

67 AHCB, Consell de Cent, Deliberacions, II-149, f. 349 (11-10-1640).

68 AHCB, Consell de Cent, Memorials de Comptes, XII-14, f. 142.

$69 \mathrm{AHCB}$, idem, f. 177 (21-11-1640).

Hispania, LXIII/1, núm. 213 (2003) 137-160 


\section{CONCLUSIONES}

En el transcurso del siglo XVII la producción impresa en Barcelona se beneficia de subvenciones económicas o «ayudas de costa» concedidas por el Consell de Cent, en función de unos criterios que no podemos aún confirmar, pero que sería interesante que fueran estudiados con profundidad. Por mi parte, he constatado que se otorgaron ayudas a autores vinculados con la institución o que escribían sobre un tema de especial interés histórico-político, lo que ocurre con la Crònica Universal de Catalunya (1609) de Jeroni Pujades.

Al igual que otras ciudades de la Monarquía Hispánica, la capital del Principado contó, además, con una imprenta encargada de las publicaciones que impulsaba y costeaba el consistorio. De entrada, la edición de impresos municipales no se puede explicar sin la intervención activa del «librero de la Ciudad», un cargo asalariado que existía desde el siglo XV y que aseguraba el suministro de papel y la encuadernación de las obras. La figura del «impresor de la Ciudad y de su Universidad» fue creada aquí de manera tardía, en 1631, aprovechando las necesidades editoriales causadas por las polémicas jurídico-institucionales previas a la Guerra de los Segadores, y sin una remuneración periódica. El cargo permaneció en manos de la familia Matevat durante más de treinta años y casi ininterrumpidamente, hasta la muerte de Catalina, la última de sus representantes; a partir de entonces y antes de la ejecución del Decreto de Nueva Planta, queda pendiente investigar el rastro de los Cormellas y de Joan Pau Martí como sucesores en el oficio de tipógrafo municipal de Barcelona.

Sebastián y Jaime Matevat eran padre e hijo y trabajaron juntos al servicio del Consell de Cent (1631-1644) en el mismo taller, por lo que no tendría sentido separar su producción, y más teniendo en cuenta que los pies de imprenta y la contabilidad de la administración local coinciden en mencionarlos indistintamente a los dos o por separado, hasta que muere el primero de ellos en 1641. Entre mis aportaciones al conocimiento de su imprenta, no creo que tuvieran también librería, o al menos no figuran en la nómina de la Cofradía de Libreros ni me consta que encuadernaran obras municipales como sí hiciera, por ejemplo, Sebastián de Cormellas. En segundo lugar, reconozco las carencias que existen por el momento en el estudio de las posibles marcas de impresor de la dinastía Matevat y desmiento algunas de las atribuciones vigentes; destacar, sin embargo, el uso exclusivo de una plancha calcográfica del grabador Joannes de Courbes con el escudo de Barcelona en las obras municipales in-folio.

Uno de los capítulos más interesantes de la producción impresa del gobierno local lo constituyen, en cuanto a la temática y los géneros que se cultivan, las repercusiones de la revuelta catalana y sus antecedentes. Durante una primera etapa, (1631-1640), los memoriales jurídico-políticos de los abogados de la Ciudad (Pere Joan Rossell, Antoni Joffreu y Joan Pere Fontanella) adquirieron un gran protagonismo. Con el estallido de la guerra se multiplicaron los avisos, relaciones de sucesos y los productos de remendería, tales como carteles, 
billetes, circulares y pasaportes, destinados a movilizar los somatenes, proveerse de víveres y medios de transporte, y garantizar la circulación de las autoridades. En convivencia con esta producción coyuntural y efímera, seguían adelante los trabajos institucionales más habituales: ordenaciones del Consell de Cent, conclusiones y cartas reales - si bien más frecuentes entre octubre y febrero de 1641, coincidiendo con la aproximación de las instituciones catalanas a Luis XIII- Durante el conflicto, Sebastián y Jaime Matevat estamparon también obras de mayor envergadura aunque, probablemente debido a la fuerte demanda de impresos en el consistorio, su monopolio se resquebrajó y a Sebastián de Cormellas le fueron adjudicados dos trabajos municipales de gran tirada, mientras que Pere Lacavalleria se encargó de una de las ediciones de 1640 de la Proclamación Católica de Gaspar Sala, que hasta ahora no había sido atribuida.

La consulta de los Memoriales de Cuentas del clavari, los pies de imprenta y, en algunos casos, las Deliberaciones del Consell de Cent y de la Vint-iQuatrena de Guerra, nos han permitido realizar un análisis cualitativo de la producción del impresor de la Ciudad y, en determinadas obras, un seguimiento exhaustivo de su proceso de publicación. Sin embargo, tenemos pocos datos acerca de los encargos y de las circunstancias de la redacción, así como de la tasación de trabajos tipográficos; además, especialmente las cuentas por suministro de papel destinado a libros y folletos consignan títulos demasiado genéricos y a menudo imprecisos (por ejemplo, «un memorial» o "negocis secrets»), lo que hace imposible un estudio pormenorizado de las entregas del librero de la Ciudad. Por último, tenemos que ser muy cautos con la mención «impresor de la ciudad» o «impresor de la ciudad y su universidad» que hallamos en las portadas, ya que también aparece en un gran número de obras que salieron de las prensas de Sebastián y Jaime Matevat a partir de 1631, pero que no fueron costeadas por el municipio ni debieron tener nada que ver con él. 


\section{ILUSTRACIONES:}

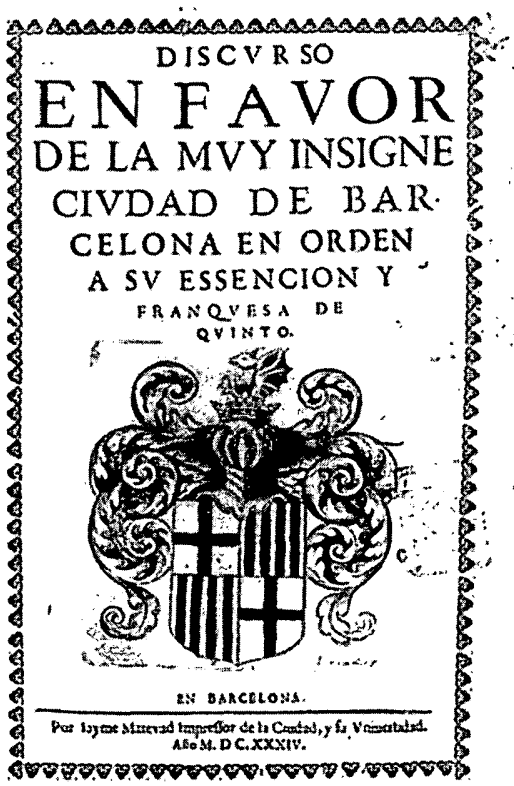

Fig. 1. Discurso a favor de la muy insigne ciudad de Barcelona en orden a su essención y franquesa de quinto. Jaime Matevat, 1634. (Portada). BUB, Fons Antic. En la parte inferior observamos la mención relativa al Impresor de la Ciudad y de la Universidad.

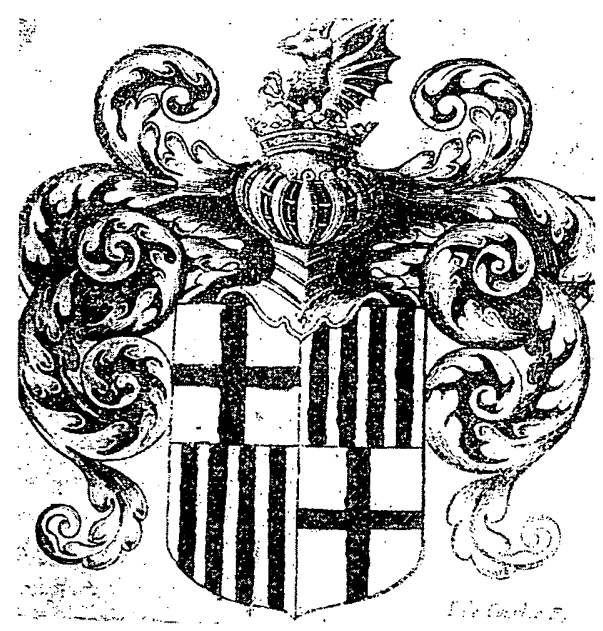

Fig. 2. Grabado calcográfico de Juan de Courbes con las armas de la ciudad de Barcelona. Siglo XVII. Se trata de la misma lámina que identifica, insertada en la portada, buena parte de la producción tipográfica municipal de Sebastián y Jaime Matevat. 